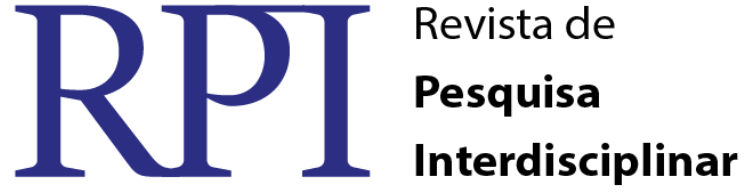

\section{FORMAÇÃO PROFISSIONAL DOCENTE EM PAÍSES LATINO - AMERICANOS E PORTUGAL: TENSÕES E DESAFIOS ${ }^{1}$}

\author{
Raimunda de Fátima Neves Coêlho ${ }^{2}$
}

\begin{abstract}
RESUMO
A perspectiva dialógica do presente texto tem como objetivo apresentar uma visão panorâmica dos estudos e pesquisas que evidenciam que o corpo docente em diferentes países, apresenta profundas e variadas heterogeneidades e desigualdades que se traduzem em termos de diferenças de formação, de valores, atitudes, opiniões e expectativas em sociedades marcadamente complexas e pluralistas. Serão apresentados alguns tópicos importantes para pensar a crescente desigualdades social diante das mudanças na economia, estrutura social e da cultura ocorridas a partir da década dos anos 1990. A exemplo, o caso dos professores da Argentina e do Uruguai, vítimas dos processos de empobrecimento social. Para tratar o tema se apoia na apresentação das diversas maneiras de entender o mundo social e as questões pertinentes à Educação sua heterogeneidade no campo profissional docente, marcada pelas instituições formadoras de professores e pelo próprio Sistema Educacional com suas regulações, controles e recursos conforme interesses de determinados setores sociais dominantes. Enfim, apresentam-se os discursos pedagógicos dominantes e até, oficializados pelas políticas de reforma durante a última década, na maioria dos países da America Latina.
\end{abstract}

Palavras-chave: Docencia. heterogenidade. discursos pedagógico. formação docente

\section{VOCATIONAL TRAINING IN LATIN AMERICAN AND PORTUGUESE COUNTRIES: TENSIONS AND CHALLENGES}

\begin{abstract}
The dialogical perspective of the present text has the objective of presenting a panoramic view of the studies and researches that show that the faculty in different countries presents / displays deep and varied heterogeneities and inequalities that translate in terms of differences of formation, values, attitudes, opinions And expectations in markedly complex and pluralistic societies. It will present some important topics to think about the growing social inequalities in the face of changes in the economy, social structure and culture that have occurred since the 1990s. For example, the case of teachers in Argentina and Uruguay who are victims of social impoverishment . In order to deal with the theme, it is based on the presentation of the different ways of understanding the social world and the questions related to Education, its heterogeneity in the professional field of teaching, marked by teacher training institutions and by the Education System itself with its regulations, controls and resources according to the interests of Certain dominant social sectors. Finally, we present the

\footnotetext{
${ }^{1}$ Pronunciamento em mesa temática no XII Seminário Analítico Internacional de Temas Interdisciplinares e IV Seminário de Pesquisa Inovadora na/para Formação de Professores

${ }^{2}$ Professora Associada I da Universidade Federal de Campina Grande - UFCG. Doutora em Medicina e Saúde pela Universidade Federal da Bahia - UFBA, integrante do Grupo Interdisciplinar de Estudos e Pesquisas em Educação, Linguagem e Práticas Sociais - CNPq/UFCG
} 
dominant pedagogical discourses and even, made official by the reform policies during the last decade, in most Latin American countries.

Key-words: Teaching. Heterogeneity. Pedagogical discourses. teacher training

\section{Introdução}

Uma visão panorâmica dos estudos e pesquisas evidenciam que o corpo docente em diferentes países, apresenta profundas e variadas heterogeneidades e desigualdades que se traduzem em termos de diferenças de formação, de valores, atitudes, opiniões e expectativas em sociedades marcadamente complexas e pluralistas.

Indicam também, desigualdades frente a posição que os professores ocupam nos diferentes espaços sociais, onde vivem e trabalham e que, essas desigualdades tendem a ampliar-se como consequência de mudanças na economia, na estrutura social e da cultura ocorridas a partir da década dos anos 1990. A exemplo, o caso dos professores da Argentina e do Uruguai, vítimas dos processos de empobrecimento social.

As diversas maneiras de entender o mundo social e as questões pertinentes à Educação torna-se evidente a heterogeneidade no campo profissional dos docentes, marcada pelas instituições formadoras de professores e pelo próprio Sistema Educacional com suas regulações, controles e recursos conforme interesses de determinados setores sociais dominantes.

Assim, os professores apresentam uma diversidade de condições e posições presente, também, entre os países latino-americanos (Brasil, Argentina, Peru, Uruguai) e no sistema educacional europeu, especificamente, em Portugal.

Com o intuito de evitar generalizações apressadas, cumpre destacar que encontram-se certas posições hegemônicas ao referir-se às ideias que os docentes apresentam em relação aos fins da educação, não afirmando existir uma espécie de cultura profissional comum nos diferentes países. (FANFANI, 2005) 
Determinadas posições ou representações do tipo, o docente como facilitador, o valor atribuído no desenvolvimento da criatividade e o espírito crítico no processo de formação de profissional docente, expressaria uma estratégia em certos discursos pedagógicos dominantes e até, oficializados pelas políticas de reforma durante a última década, na maioria dos países da America Latina.

As múltiplas diversidades entre os docentes são inevitáveis, principalmente, por se tratarem de sociedades complexas que tendem ao pluralismo. Compreende-se ser inadmissível que há docentes que vivem uma situação de pobreza e exclusão social, que não possam ter acesso a bens materiais e simbólicos básicos, como os consumos culturais e recursos tecnológicos para realização profissional. (FANFANI, 2005). Este autor (2005, p. 262), ainda, destaca que a diversidade é uma riqueza e a desigualdade é uma injustiça e não somente deve ser mostrada, denunciada, mas também combatida.

Dito isto, indaga-se: que tensões e desafios permeiam a formação profissional docente nos diferentes países latino-americanos e europeu (Portugal)? Questões como esta e outras, marcam presença nas pesquisas e discussões em tempos de exigências frente às demandas sociais na sociedade contemporânea. Para tanto, torna-se relevante apontar o caminho que ora conduzirá esta discussão, a saber: inicialmente, apresentar-se-á uma visão panorâmica sobre a profissão docente no contexto de alguns países da America Latina e europeu, no caso Portugal. Em seguida, discutir-se-á acerca de tensões e dimensões subjacentes que envolvem a vocação/profissão/profissionalização docente e, finalmente, compreender algumas implicações desprendidas da investigação (FANFANI, 2005), postas como desafios, ou melhor, um convite à luta, uma provocação à formação profissional docente. Assim, discutese inicialmente, sobre três dimensões presentes na identidade docente como categoria social, a saber:

\section{Vocação e profissão: uma primeira dimensão conflituosa}

Durante muito tempo compreendia-se que para ser um bom professor o mais importante era ter vocação, entendida como um dom associado com um dever e uma obrigação. Todavia, nas discussões dessa época, por volta da segunda metade do século XIX, outro grupo assumia uma posição contrária. Os profissionais que não negavam a importância da vocação, mas insistiam afirmar que para ser bom professor teria que aprender a usar RPI Revista de Pesquisa Interdisciplinar, Cajazeiras, v. 1, Ed. Especial, 41-52, set/dez. de 2016. 
conhecimentos científicos, através de uma formação em instituições especializadas. Então, cada setor propunha seus argumentos que expressavam interesses e posições sociais diferentes.

Do ponto de vista teórico, a vocação opõe-se a profissão. Conforme Fanfani (2005, p.264) a vocação não exige mudança, não exige recompensas materiais. Esse modelo de papel tem consequências sociais que nem são percebidas pelos docentes que se identificam com esse modelo. Em contraposição o trabalho profissional é sempre parcial e não se exerce todo tempo e nem em todas as circunstâncias.

As investigações nos quatro países evidenciaram que a grande maioria dos docentes considerou sua atividade como vocacional e profissional ao mesmo tempo, cujo conceito aplicado nessas investigações associou-se à ideia de profissão com o uso de conhecimento formal no exercício da atividade docente (FANFANI, 2005). Além desse conceito, outros foram importantes para definir o componente de profissionalização, isto é, a autonomia da produção de serviço e o elevado reconhecimento ou prestígio que se outorga ao profissional.

No magistério contemporâneo dá-se o predomínio da combinação de elementos vocacionais e profissionais, como característica da profissão docente. Esta definição subjaz uma série de tensões e conflitos, uma vez que a convivência de elementos contraditórios gera tensões, que diante de determinadas reivindicações e demandas dos docentes podem ser influenciadas pela antiga ideia de vocação.

Esta tensão entre valores associados com a vocação e valores da profissão, precisa ser administrada em cada momento histórico, pois, ambos componentes são importantes para garantir a qualidade e a excelência do serviço educativo. Provavelmente, pode-se reduzir a tensão quanto ao elemento vocacional redefinindo-o, abandonando a ideia de vocação como predisposição inata, reconhecendo que se trata de uma construção histórica e cultural. Também, renunciar a ideia que associa a vocação com o desinteresse. Porém, entendida a partir da ideia de um compromisso e uma atitude de responsabilidade e respeito com a pessoa e o grupo de aprendizes (FANFANI, 2005). Em outras palavras, ressignificar o termo vocação no sentido político e não trazer o termo vocação como sacerdócio.

\section{Discutindo a profissionalização docente}

RPI Revista de Pesquisa Interdisciplinar, Cajazeiras, v. 1, Ed. Especial, 41-52, set/dez. de 2016. 
O conceito de profissionalização utilizado nesta discussão compreende a valorização e investimentos no conhecimento (pedagógico, didático, entre outros), como componente básico desse contexto. Nas lutas, anos 1960 e 1970 em muitos países latino-americanos, a identidade dos docentes foi definida como trabalhadores, caracterizados como sujeitos coletivos que compartilham direitos trabalhistas, interesses e demandas com outros assalariados, através de suas organizações sociais (FANFANI, 2005, p. 271).

A tensão entre profissional e trabalhador tende a enfraquecer, na medida em que se elevam as qualificações do conjunto dos trabalhadores. Nas condições atuais, a reivindicação de profissionalização não se opõe às reivindicações dos direitos trabalhistas, também, se associa ao domínio de competências científicas e técnicas mais complexas, a maiores graus de controle sobre o trabalho que realizam e o prestigio e reconhecimento social mais elevados. Características essas, fundamentais à profissionalização docente.

Finalmente, não se pode deixar de mencionar fatores que tem efeitos contraditórios sobre a profissionalização docente como as dificuldades e desafios da questão social, cujos efeitos são obstáculos para o avanço e a superação profissional dessa categoria social. A grande maioria dos docentes não somente sabe, como também vive e sofre cotidianamente os múltiplos efeitos da questão social contemporânea sobre seu trabalho profissional.

\section{Trabalho docente e a política: uma terceira dimensão}

Uma terceira dimensão geradora de tensões refere-se a combinação de vocação e profissionalização, com a consciência das dimensões políticas envolvidas no trabalho de socialização e subjetivação das novas gerações.

No campo da política, diferenciam-se duas posições típicas: uns, identificam seu trabalho com adesão a valores universais próprios da condição humana e outros, reconhecem que no ensino não se pode tomar posição diante de questões, temas e destaques que se referem ao tempo presente de cada sociedade nacional.

A politização aqui definida implica uma tomada de posição frente aos temas que estruturam o campo político de uma determinada sociedade, em um movimento histórico e não com a militância em um partido político específico.

RPI Revista de Pesquisa Interdisciplinar, Cajazeiras, v. 1, Ed. Especial, 41-52, set/dez. de 2016. 
Neste sentido, toda política supõe uma postura em relação aos valores universais, aos temas que estão presentes no momento atual ou na conjuntura. Convém, destacar que na Argentina e, parcialmente no Brasil, a preferência pela politização é mais provável entre aqueles que mais dependem do salário docente para satisfazer suas necessidades básicas (FANFANI, 2005). Assim, as evidências indicam que na cultura dos que exercem o trabalho docente, existem bases sólidas para construir novas sínteses que coloquem o coletivo docente à altura das novas circunstâncias. Uma vez discutidas as tensões nos países latino-americanos, dá-se seguimento à discussão do processo de formação docente em Portugal.

\section{Discutindo a formação profissional docente em Portugal: uma síntese necessária}

A partir dos anos 1990 o sistema educacional de Portugal viveu o fenômeno designado por massificação do acesso ao ensino superior e nesse ínterim, dá-se a intensificação de debates sobre a necessidade de se garantir a qualidade de formação. Nos últimos anos os discursos focados na qualidade e na avaliação da qualidade tem vindo a impor-se. Associado a esse foco, outros discursos apontam para importância da internacionalização.

Nesta direção, impõe-se como critério de qualidade a necessidade do conhecimento produzido e divulgado em revistas indexadas - investigação no ensino superior e avaliada pela qualidade que lhes é reconhecida. Desses discursos decorrem desafios como: a organização dos cursos, os modos de trabalho pedagógico dos docentes e quanto ao tipo de investigação em que os docentes se envolvem.

No âmbito da formação de professores, princípios e diretrizes são definidos após Declaração de Bolonha (2003) - em que os cursos de formação adaptaram-se aos compromissos de Bolonha (Decreto - lei $n^{\circ}$ 74/2006). Esse parâmetro definiu-se observando aspectos como: avaliação e organização dos cursos conforme as estruturas definidas por Bolonha; a formação passou a ocorrer ao grau de mestrado, em razão da falta de critérios específicos para formação dos ensinos básicos e secundários, no quadro do Processo de Bolonha - PB. Essa situação gerou retrocesso no sentido de tornar concreta a relação teoria e prática na formação inicial de professores (LEITE, 2012).

De acordo com o PB, os cursos de formação em Portugal, estão comprometidos com uma formação conforme DALE (2004) aponta à existência de uma agenda globalmente estruturada para construção de uma cultura educacional mundial comum, cujo objetivo RPI Revista de Pesquisa Interdisciplinar, Cajazeiras, v. 1, Ed. Especial, 41-52, set/dez. de 2016. 
consiste em elevar a competitividade internacional do sistema europeu do ensino superior. Robertson (2009) analisa que a Declaração Bolonha recorre ao ensino superior para concretização de um projeto político que gerasse efeito de ordem econômica.

Comungando com as ideias de Robertson (2009), Leite (2012) afirma que o desenvolvimento do PB em Portugal, ocorre numa tensão entre a massificação e pela qualidade. A massificação, entendida como consolidação de um ensino superior de massa e, a qualidade no sentido de valorização da investigação e da informação ao longo da vida. Constatando-se, assim, a impossibilidade de uma formação para um futuro papel de professor (a).

No tocante ao discurso acadêmico, Leite (2012) destaca algumas preocupações e perspectivas abordadas por estudiosos, inclusive a própria, na área da formação tanto em países latino-americanos quanto em Portugal como: um primeiro grupo, tem sustentado a importância de se promover uma formação que predisponha para mudança (NÓVOA, 1992, 2009; LEITE, 2009); o segundo, defende uma formação que permita o desenvolvimento de competências de compreensão da educação escolar nas suas dimensões sociais e nas especificidades culturais dos alunos (LEITE, 2002; CANDAU, 2009).

Bolívar $(1992,1994,2000,2002,2004)$ tem reconhecido que a formação deve ampliar-se ao desempenho de papeis na escola e ao conhecimento da organização escolar. Outro discurso acadêmico realça a importância de condições que socializem os professores na profissão (PERRENOUD, 1992, 1994, 2000, 2002; DUBAR, 1997; ANASTASIOU, 2003; TARDIF; LESSARD, 2005). E a quem é exigido um contínuo questionamento na lógica do Aprender a Aprender (SCHON, 1992; ZEICHNER, 1993; ALARCÃO, 2004).

Em termos de instituições mundiais, a UNESCO tem defendido a necessidade de (re) orientar a formação de professores, em função da responsabilidade que lhes é atribuída nos processos de mudança global a nível social, político e econômico (LEITE; FERNANDES, 2002; LEITE, 2005). Conclui-se, assim, que o discurso sobre a formação de professores em Portugal diante da reconhecida complexidade que acompanha o exercício da docência e que os professores também são elementos importantes na institucionalização de mudanças educacionais e sociais, Leite (2012, p. 114) propõe dizendo: “[...] é urgente interrogarmo-nos sobre os efeitos que poderá ter uma formação de professores organizada na lógica que pressupõe o Processo de Bolonha [...]”. Portanto, eis o desafio para os países que assinaram a Declaração de Bolonha.

RPI Revista de Pesquisa Interdisciplinar, Cajazeiras, v. 1, Ed. Especial, 41-52, set/dez. de 2016. 


\section{Compreendendo os desafios do profissional docente: um convite às possibilidades de mudanças...}

Pensar em pressupostos de políticas de mudança na educação, implica atentar-se ao conjunto de valores que fundamentam e direcionam uma política que favorece o processo de construção de uma sociedade mais justa e livre. Neste sentido, a mudança na educação implica colocá-la ao nível dos desafios contemporâneos, isto é, mudar os modos de fazer as coisas nos diferentes sistemas de ensino, não perdendo de vista os fatores estruturais, uma vez que sem recursos e sem um sistema adequado torna-se impossível a concretização de fazeres de qualidade.

Nesta direção, Fanfani (2005, p. 278) argumenta que os dados apresentados resultantes de investigações educativas nos países da America Latina (Argentina, Brasil, Peru e Uruguai) constituem-se em

[...] información acerca de las múltiples dimensiones objetivas y subjetivas del colectivo docente resulta útil para quien quiera introducir "elementos modificadores" tanto en el contexto social e institucional del trabajo docente, como en las reglas que regulan su carrera (acceso y condiciones de trabajo, promociones y ascensos, etc.), el sistema de formación inicial y permanente, y los sistemas de recompensas materiales y simbólicas (salario, reconocimiento social, etc.) que funcionan como incentivos a su desempeño profesional. [...]

Então, nesta visão de possibilidades de mudança, convém destacar que os docentes em suas ações não as realizam apenas cumprindo determinações estruturais (regras e recursos que organizam suas práticas) mas, também, por serem sujeitos capazes de dar sentido e controle de suas próprias ações.

Compreende-se, pois, a importância dada na literatura específica para que as instituições de formação docente caminhem numa perspectiva de qualidade da oferta educativa, que passa fundamentalmente pela qualidade de práticas nas aulas. Desse modo, interpretando os estudos e investigações latino-americanas, em especial, Fanfani (2005), pode-se considerar alguns desafios e ou implicações resultantes dessas pesquisas, a saber: como primeiro pressuposto de política para formação profissional implica dizer que toda política docente deve ser integral, isto é, precisa contemplar intervenções articuladas em três RPI Revista de Pesquisa Interdisciplinar, Cajazeiras, v. 1, Ed. Especial, 41-52, set/dez. de 2016. 
dimensões: no recrutamento da formação inicial e permanente, nas condições de trabalho (divisões do trabalho pedagógico, carreira, contexto institucional de trabalho e outros) e no sistema de estímulos e recompensas materiais e simbólicas (salário e reconhecimento social).

No entanto, ao tratar-se de mudanças práticas e subjetivas (mentalidades, conhecimentos, atitudes, valores e outros), torna-se relevante que essas políticas estratégicas possam ter uma sustentação na sociedade, pela via das denominadas políticas de estado, mediante acordos e consensos para se obter resultados diante da complexidade das transformações a serem realizadas.

No tocante aos fins prioritários da educação e acerca do papel profissional do docente merecem ser discutidos à luz de uma revalorização e renovação da ideia tradicional de transmissão cultural. Isto implica refletir que a simples adesão às ideias de criatividade e espírito crítico, caso não estejam acompanhadas de um compromisso com a tarefa de apropriação da cultura e da ciência de validade universal, pode tornar-se apenas em um discurso que não traz resultados práticos, para o desenvolvimento de aprendizagem das pessoas.

Destaca-se aqui, a importância dos profissionais da educação no processo de formação de novas gerações, no intuito de colocar essa questão em discurso e reflexão tanto nas instituições formadoras de docentes, quanto no campo da investigação em nível nacional e internacional.

A formação docente tanto a inicial quanto a permanente, precisa preocupar-se com as demandas expressadas pelo docente em termos de conteúdos, de estratégias pedagógicas para sua formação. É importante considerar que determinados conteúdos e perspectivas possam ser incorporadas aos programas de formação, atentando para certos cuidados, principalmente, não incluir apenas preferências temáticas que traduzem o coletivo docente. Porém, dar atenção a certos grupos específicos de docentes, à exemplo, os que apresentam temores e ou resistências ao uso das novas tecnologias da informação e da comunicação na prática profissional.

Nessa direção, atentar para uma formação em que possa-se prever recursos e instrumentos necessários de motivação e mobilização de interesses, requisitos básico de aprendizagens exitosas. Quanto aos programas de formação docente atentarem para dispositivos institucionais que favoreçam a produção, sistematização, valorização e difusão do conhecimento da experiência docente, pois, geralmente os programas enfatizam mais os RPI Revista de Pesquisa Interdisciplinar, Cajazeiras, v. 1, Ed. Especial, 41-52, set/dez. de 2016. 
conteúdos vulgarmente teóricos que, na maioria das vezes, estão afastados dos problemas enfrentados cotidianamente em seus próprios contextos de trabalho.

Com relação às qualificações dos docentes, não há dispositivos para facilitar o diálogo e o intercâmbio entre saberes teóricos aprendidos em sistemas formais de formação e os saberes práticos desenvolvidos em serviço. Interrelação essa, necessária ao início da carreira e que necessitaria instituir-se dispositivos de apoio e intercâmbio entre novos e experientes docentes, tendo em vista aprender através do trabalho conjunto com colegas sábio por experiência, numa relação de conhecimento prático e pedagógico formal.

A carreira docente em termos de aspirações de trabalho, corre o risco de ver-se frustrada à medida que essa carreira não prevê espaços de superação, que não implique no abandono de sala de aula. Ainda, sobre a carreira docente não se pode pensar em hierarquizar o trabalho docente com estratégias discursivas do tipo, em fazer de cada docente um pesquisador, uma vez que não se profissionaliza um docente quando o torna apenas investigador, fazendo-o abandonar a docência. A hierarquização do trabalho docente passa por uma reivindicação da especificidade e complexidade da tarefa de ensino-aprendizagem, de modo que sejam reconhecidos socialmente como outros profissionais, tais como: os médicos, engenheiros, advogados e outros.

No que diz respeito ao impacto de todas as dimensões da questão social nas instituições educativas, torna-se obrigatório a tomar decisões políticas estratégicas. Nos novos contextos há duas estratégicas políticas que podem ser aplicadas de forma articuladas como: reconstruir políticas públicas integrais e integradas que possam garantir condições sociais de aprendizagem as novas gerações e, uma outra, que trata do ensino não somente pedagógico, mas, que assuma grande parte da responsabilidade de garantir a satisfação de uma série de necessidades básicas das novas gerações. A escola de tempo integral deve ser um recurso que também atenda os setores pobres e excluídos para garantir a socialização e a aprendizagem das gerações.

A complexidade crescente da tarefa docente tem forçado a delinear novos esquemas normativos e institucionais de modo a estruturá-la. Convém destacar que o modelo escolar clássico privilegia o trabalho individual e isolado de cada docente em sua aula. Esse modelo de trabalho precisa ser substituído por outro que favoreça o trabalho em equipe entre docentes de diferentes níveis, especialidades e campos disciplinares. Precisa, interagir com outros agentes profissionais, passando de docente individual para docente coletivo.

RPI Revista de Pesquisa Interdisciplinar, Cajazeiras, v. 1, Ed. Especial, 41-52, set/dez. de 2016. 
Por último, as informações dessa investigação indicam que docentes vivem excluídos da cultura. A sociedade espera dos docentes que sejam mediadores de aprendizagem das novas gerações, contraditoriamente esses profissionais, muitas vezes, encontram-se excluídos de certos consumos culturais básicos. O acesso a bens culturais como: a leitura, o teatro, gêneros musicais e outros, não fazem parte de suas vidas, indicando um empobrecimento do próprio capital cultural. É preciso desenvolver políticas culturais dirigidas aos futuros docentes como aos docentes em exercício. Para tanto, as instituições de formação docente precisariam tornar-se em espaços de produção e difusão cultural, tanto para o corpo docente quanto para comunidade em geral.

E, ainda, em contraposição a proliferação de cultura de massas, tão presente na degradação das condições de civilidade, a escola cabe desenvolver a criação de uma cultura genuína, em que possa suscitar às novas gerações disposições e sensibilidades estéticas e éticas, que contribuam para civilidade e convivência como garantia de uma integração social

\section{À título de conclusões}

As orientações aqui expostas, resultantes de investigações (FANFANI, 2005) em países latino-americanos como: Brasil, Argentina, Peru, Uruguai foram designadas como voluntárias. Contudo, considera-se relevante (re) afirmar, refletindo que é preciso sair da sensação de impotência e fatalismo diante de algumas tendências perversas do desenvolvimento social e que se faça como convite uma reivindicação da vontade e da ação coletiva, uma vez que as evidências indicam a existência de condições objetivas e subjetivas para criar e renovar o trabalho docente em função de um projeto social.

Conclui-se que em Portugal os discursos acadêmicos convocam o coletivo de professores ao desafio de questionar o desenvolvimento do Processo de Bolonha em suas práticas educativas, pois, a formação profissional oferecida nesse país não propicia para o verdadeiro papel do professor.

Destaca-se, também, que torna-se evidente a existência de uma tendência preocupante de formação de professores em âmbito mundial, em que as instituições formadoras não estão imunes às tendências presentes na sociedade contemporânea, pautadas pela lógica dos interesses hegemônicos orientados pelo mercado e pelo consumo, exigindo formação rápida e RPI Revista de Pesquisa Interdisciplinar, Cajazeiras, v. 1, Ed. Especial, 41-52, set/dez. de 2016. 
voltada para as demandas advindas das esferas da produção, perdendo de vista o caráter político, humanista, emancipador e o domínio de conhecimentos científicos e técnicos mais complexos necessários à formação profissional docente.

\section{Referências}

ALMEDA, Maria Isabel de. Formação do Professor do Ensino Superior: desafios e políticas institucionais. $1^{\mathrm{a}}$ ed. - São Paulo: Cortez, 2012

CUNHA, Maria Isabel da \& BROILO, Cecília Luiza; (orgs). Qualidade da Educação Superior: Grupos Investigativos internacionais em diálogo. Araraquara, SP: Junqueira \& Marin, 2012

DALE, Roger. Globalização e Educação: demonstrando a existência de uma "cultura educacional comum" ou localizando uma "agenda globalmente estruturada?". Educação e Comercial e Sociedade, Campinas, v.25, n. 87, p. 423-460, mai/ago. 2004

FANFANI, Emílio Tenti. La condición docente: análisis comparado de la Argentina, Brasil, Perú y Uruguai. - $1^{\text {a }}$ ed. -Buenos Aires: Siglo XXI Editores Argentina, 2005

GUIMARÃES, Célia Maria et al. (orgs). Formação e profissão docente. -Araraquara, SP: Junqueira \& Marin, 2011

LEITE, Carlinda. Qualidade da Educação Superior e Formação de Professores - Uma análise a partir da situação em Portugal. In: CUNHA, Maria Isabel \& BROILO, Cecília Luiza. (orgs). Qualidade da Educação Superior: Grupos Investigativos internacionais em diálogo. Araraquara, SP: Junqueira \& Marin, 2012

ROBERTSON, Susan L. O Processo De Bolonha Da Europa Torna-se Global: modelo, mercado, mobilidade, força intelectual ou estratégia para construção do estado? Revista

Brasileira de Educação, v.14, n. 42, p. 407-422, 7 set/dez, 2009 